\title{
Report on the EFSUMB 2014 activities from EFSUMB President Christoph F. Dietrich
}

During the last year of ultrasound there are many topics to be mentioned and it is my pleasure to report on the EFSUMB past year and 2015 plans and visions.

The EUROSON congress took place in Tel Aviv, Israel locally organized by charming Prof. Diana Gaitini. This important and multidisciplinary meeting and wonderful event took place during a peaceful period. I am so sorry that the political situation dramatically changed a few weeks thereafter. I will never forget EUROSON 2014 and I deeply wish that peace and happiness come back to our friends in Israel.

The next EUROSON congress 2015 takes place in Athens, Greece. Please follow our invitation to this historical and modern city in November 6 to 8 . The next WFUMB congresses will take place in Orlando, USA 21-25 March 2015 (hosted by AIUM) and the subsequent meeting in Taipei, 13-17 October 2017 (hosted by AFSUMB). EFSUMB was represented at various meetings in 2015 including ECR, DLT and UEG Week in Vienna. We are now working to establish a closer collaboration with EASL.

The successful EFSUMB guidelines published in our official journal "Ultraschall in der Medizin / European Journal of Ultrasound" have gained more and more attention. The impact factor (IF) of our journal has gained an impressive 4.6 which is the highest IF of an interdisciplinary ultra-

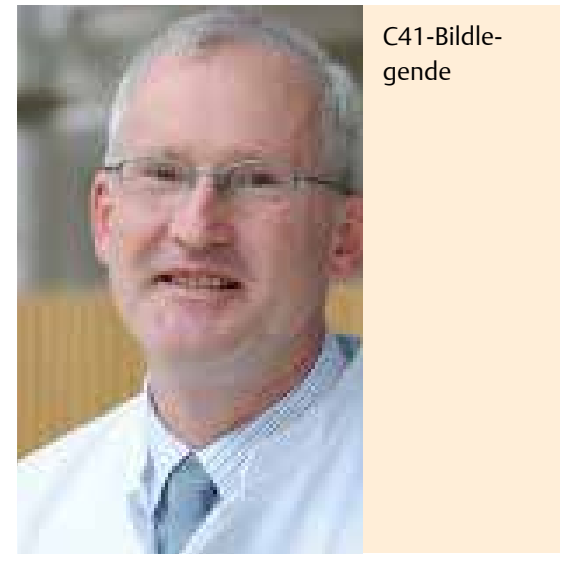

sound journal worldwide. The recommendations on the use of ultrasound elastography have been frequently cited. Part 1 deals with the basics of ultrasound elastography, aimed at clarifying the different modalities currently on the market, which produce different types of elastography, including strain elastography and various shear wave modalities. Part 2 presents the 
current recommended clinical applications. In addition, a position statement on safety of elastography has been released by the ECMUS (Safety) Committee. All EFSUMB publications can be freely downloaded via our website www.efsumb.org. The current and future guidelines are part of EFSUMB's forefront worldwide efforts to improve and distribute scientific knowledge of new ultrasound techniques according to our constitution.

We are encouraged to prepare EFSUMB guidelines on ultrasound-guided interventions. Such procedures have revolutionized everyday clinical practice in recent decades. The advantages of ultrasoundguided interventions include an unsurpassed sharpness of detail and excellent controllability owing to the real-time visual display, the wide availability of ultrasound equipment, and a simple and straightforward practical technique. This makes it all the more surprising that guidelines of interventional ultrasound have not been previously published. The guidelines, discussed in Frankfurt at the end of January 2015, will consist of 4 main parts:

- Part I dealing with general aspects of interventional ultrasound.

- Part II with diagnostic procedures.

- Part III with treatment procedures using the transcutaneous approach.

- Part IV deals with specific diagnostic and therapeutic procedures using endoscopic ultrasound.

The EFSUMB website has been modernized and updated on a regular base. The motor behind our website is Suzanne Cain always stimulating us with new ideas. It might be of interest for our members that an article on the use of the website has been published (The EFSUMB website, a guide for better understanding. Med Ultrason 2013; 15: 215-223), which can be downloaded via our website www.efsumb.org.

The chapters of our successful EFSUMB Course Book were reviewed 2014 and will be updated on the EFSUMB-website 2015. The printed version with colored images is still available and can be ordered at a very cheap price via efsumb@efsumb.org. All chapters are free to download from our EFSUMB-website www.efsumb.org. The videos on examination technique and anatomy are now combining the ultrasound image and position of transducer in 1 screen and will be uploaded in the next month. The Student Edition of our EFSUMB Course Book is still work in progress. We certainly encourage our members to use and to suggest further improvements.

The Educational Portal also hosts other ePub books which can be downloaded for free, e.g., "Hepatic elastography using ultrasound waves”, edited by Prof Ioan Sporea and Dr Roxana Sirli and "The safe use of ultrasound in medical diagnosis", edited by Prof Gail ter Haar.

The EFSUMB Case of the Month (CoM) was initiated in 2008. Since this time the CoM is still the most visited website page of EFSUMB. Due to the efforts of the current Editor Paul Sidhu, CoM has been translated in several languages. New cases from all EFSUMB members are welcome and can provide great visibility to the authors.

EFSUMB's membership is stable with more than 19000 members. The federation of 27 smaller and larger societies serves the interests of all our members being the voice of EFSUMB in Europe. The restructuring of the European leadership of some ultrasound societies, e.g., in Finland and Sweden, is hopefully under way.

EFSUMB has reduced its costs by increasing efficiency to maximize the benefit for our members. The expenditures have been explained in a recent newsletter [Ultraschall in Med 2014; 35-36; http:// www.efsumb.org.), indicating not only the expenses in detail but also a better understanding of the value of our European team. EFSUMB like many European institutions is under enormous pressure to reduce costs. It has to be noted that nearly $40 \%$ of all income is obtained from the memberships fees and that this is nearly $45 \%$ of EFSUMB expenditure (after removing the WFUMB costs), thus National Societies are contributing for 55\% to EFSUMB activities (not $100 \%$ as may be thought). An EFSUMB financial strategy meeting is planned for 2015, please give your input.

We will have to encourage all our member societies to supply the e-mail addresses of our individual members. This is a prerequisite to further drop the costs. In addition, more information of EFSUMB activities of the individual national members is warmly welcome. This could be in English or in national languages.

The internet supported conference calls have been successfully incorporated into EFSUMB communication within the ExB and the committees. The software facility allows meetings on regular basis at almost no additional cost. The mix of experienced and new officers continued the committee work and gave new impulses. In 2014 the EFSUMB Education Committee (EPSC) approved 9 Euroson Schools in 8 countries, including the ever popular Hannover CEUS School. The EPSC endorsed 26 courses. All information about the educational activities can be found on our website.

The concept of EFSUMB Ultrasound Learning Centres (ULC) in established and renowned ultrasound departments at universities, hospitals and in medical practices, led by respected ultrasound practitioners, approved by EFSUMB, where participants can spend a period of time to learn and to improve their knowledge in various applications of ultrasound, is presented to the Board. In its first year 2014, 4 ULC's were established: Timisoara, Cluj Napoca, Berlin and Bergen. The teaching language is English if participants are from outside the host country. Participants from outside Europe are also welcomed, with the language of instruction expected to be English.

In 2015 we will continue to develop and enhance our core activities including the educational programs also in setting clinical standards, further development of elearning and the important public relations activities that take place across EFSUMB Europe. We will also more actively engage with the development and promotion of research represented by our Scientific Corner.

I am deeply impressed by the daily work load of our marvelous secretary, Lynne Rudd. Dear Lynne, thank you so much for your dedication to EFSUMB and friendship. I am very thankful to have such good friends and colleagues in the ExB which not only successfully serve EFSUMB in more difficult times but also allow best communication and collaboration. The team spirit of our various EFSUMB committees led to important interaction. The Board of Delegates represents the important base connecting with our National Societies also in 2015 building the European Ultrasound Community.

Christoph F. Dietrich

EFSUMB President 2013-2015 